\title{
PMIP key dates and achievements over the last 30 years
}

\author{
Pascale Braconnot' ${ }^{1}$, M. Kageyama', S.P. Harrison², B.L. Otto-Bliesner ${ }^{3}$, A. Abe-Ouchi', M. Willé', J.-Y. Peterschmitt ${ }^{1}$ \\ and N. Caud ${ }^{1}$
}

\section{Over the last 30 years, PMIP has made significant progress in the development of Earth system models, climate reconstructions, and model-data comparisons. It has contributed greatly to our understanding of climate sensitivity, ocean circulation and abrupt events, the hydrological cycle, the linkages between climate and ecosystems, and climate variability.}

\section{From infancy to a mature project}

During the last 30 years, the Paleoclimate Modelling Intercomparison Project (PMIP) has fostered synchronized model simulations, climate reconstructions, and modelmodel and model-data comparisons for key climate periods in the past (Fig. 1). The major objectives of the project developed for the first phase of PMIP are still valid today (see Joussaume and Taylor, this issue): to understand the mechanisms of climate change, test models in a climate context different from modern, and define evaluation criteria that are relevant to assess the credibility of future climate projections. However, the project has refined these objectives in four successive phases (Fig. 1 and 2).

The PMIP niche is to produce paleoclimate simulations with the same general circulation models (GCMs) used for future climate projections. During PMIP's lifetime, these models have evolved from atmosphere-only to Earth system models (Fig. 1), initially through the inclusion of either ocean or vegetation couplings with the atmosphere. The choice of the complexity of the model used, such as the inclusion of the carbon cycle or interactive aerosols, still varies across modeling groups. However, currently, the main focus is on full integration of the different components of the system. PMIP has provided a way both to test different climate feedbacks related to land surface, ocean, or ice sheets, and to improve understanding of the relationship between climate and variations in terrestrial and marine biogeochemistry. Because of its unique focus, PMIP has been endorsed from the beginning by PAGES and the World Climate Research Programme (WCRP) through its core project Climate Variability (CLIVAR) and subsequently the Working Group on Coupled Models (WGCM). These endorsements have allowed PMIP to maintain strong connections to the modeling and climate reconstruction communities throughout the last 30 years.

PMIP encourages growth in its activities while maintaining a focus on a limited number of key questions. It plays a key role by providing results in the open database for global climate simulations supported by WCRP (Peterschmitt et al. 2018). These results have been used for studies well beyond those originally envisaged by people outside the main PMIP community, including for impact studies, or to assess changes in biodiversity or ecological niches.

\section{Evolution of the context and scientific questions}

PMIP1 highlighted robust model responses to external forcings for the mid-Holocene and the Last Glacial Maximum (LGM) and discussed model uncertainties. The number of independent climate indicators from different natural archives has increased with time, allowing for tests of the modeled response to the forcings of the land, ocean, and ice sheets (see Bartlein et al. and Jonkers et al. this issue). The role of carbon cycle and other feedbacks has been considered since PMIP2. PMIP3 introduced a focus on analyses of interannual-to-centennial climate variability (Braconnot et al. 2012). New methodologies for model-data comparison have been continuously developed, from simple visual comparisons, to application of specific metrics, and finally to the use of forward modeling of the various climate indicators such as water or carbon isotopes. The importance of model-data comparison meant that there had to be a balance between the use of a strict experiment protocol to be able to understand model differences and more flexible protocols allowing different groups to sample uncertainties in boundary conditions.

New periods and questions have been included progressively in PMIP to address a broader range of external forcings and climate issues. These choices were discussed and made at the regular PMIP meetings every 2-3 years (Fig. 1). A challenge has been to foster collaboration around key periods, with standardized simulations and associated databases, while also acting as a network to share new results and sensitivity experiments that improve our understanding of major climate feedbacks. The early Holocene and last glacial inception were included in PMIP2 to address questions about water cycle feedback from the ocean and vegetation, and the role of snow and ice sheets (PMIP 2000). Multi-model results were developed for the last interglacial in PMIP3. However, a common protocol for the last interglacial was only proposed in PMIP4 (Otto-Bliesner et al. 2017). Pre-Quaternary climates have also been included since PMIP3 because of their ability to provide constraints on climate sensitivity (Haywood

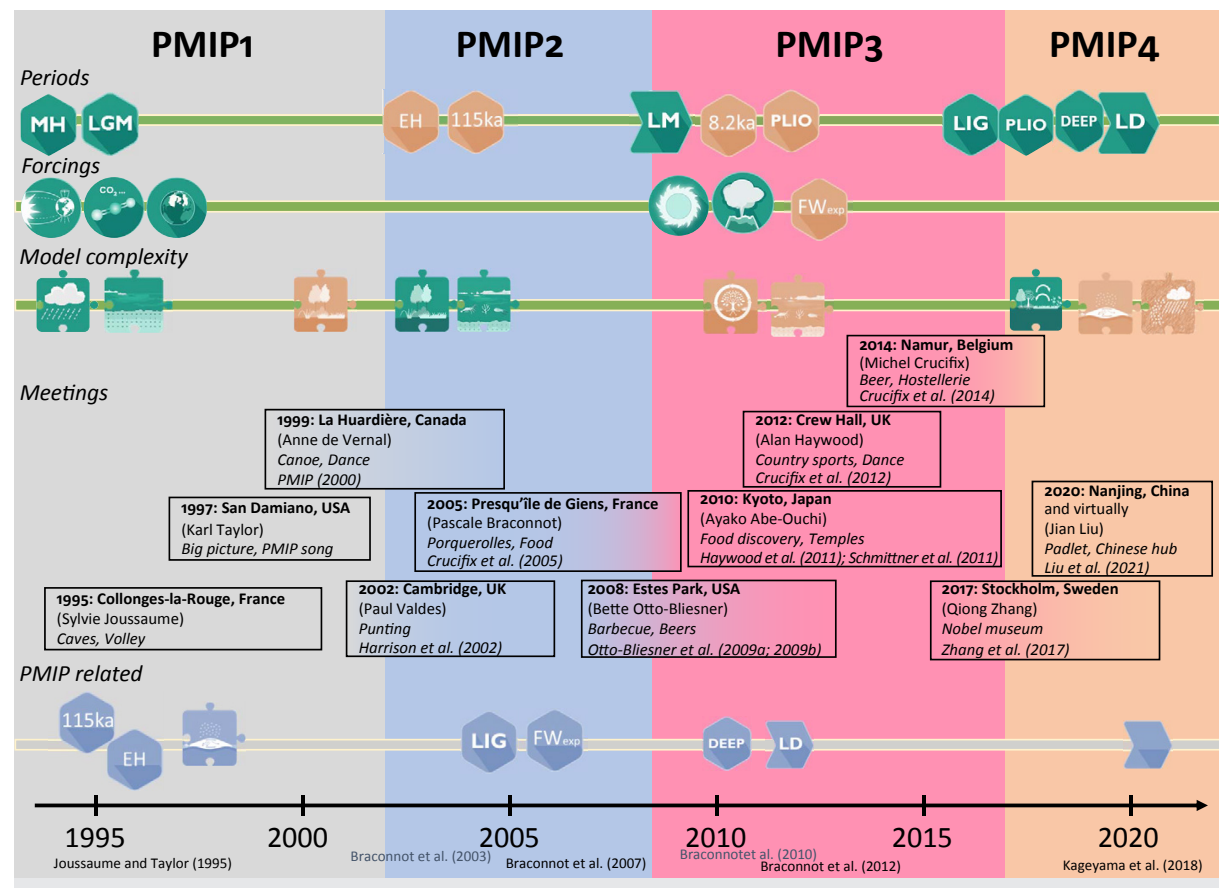

Figure 1: PMIP phases highlighting major meetings (date, location, host, activities, and meeting report), together with the key periods, external forcings, and model complexity represented with small infographics either as core PMIP activities (green), small groups (orange), or as part of the wider network (blue). MH = Mid-Holocene, LGM = Last Glacial Maximum, EH = Early Holocene, $L M=$ Last Millennium, PLIO = Pliocene, DEEP = deep time, LIG = Last Interglacial, and LD = Last Deglaciation. When a number is included (e.g. "115ka"), it refers to the exact period as discussed during PMIP meetings. 


\section{Mid Holocene : 6 - o kyr BP}

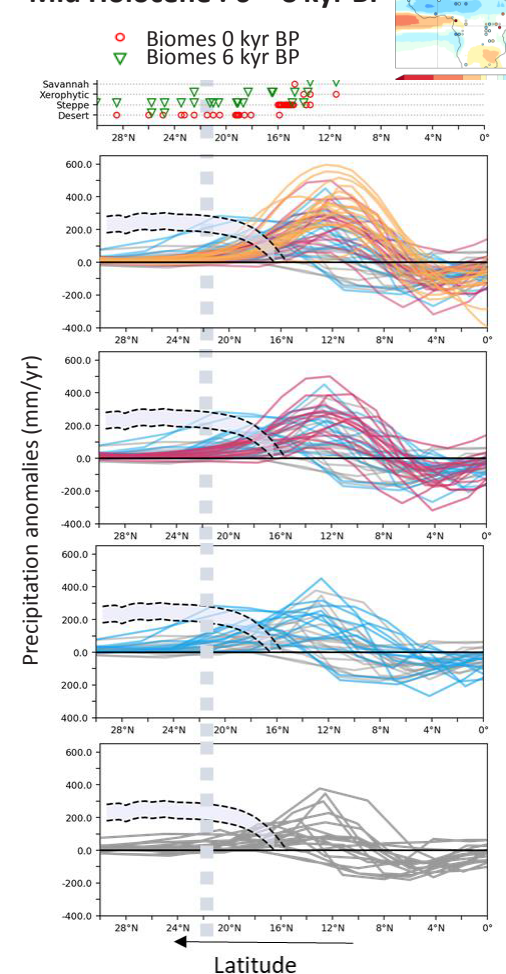

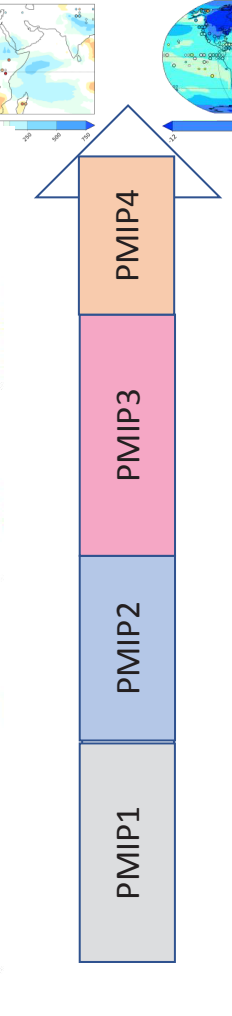

LGM 21- o kyr BP

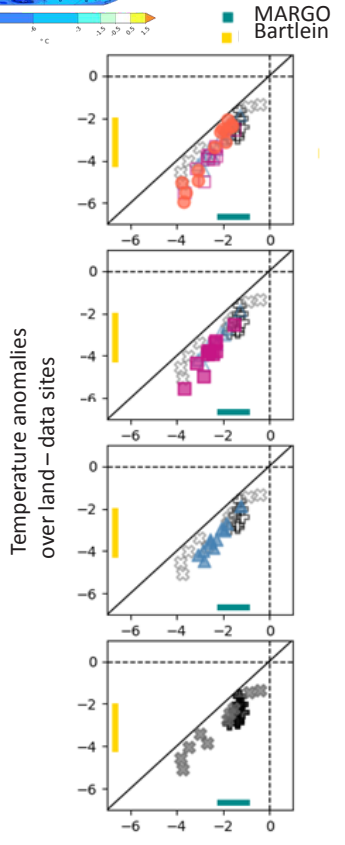

Temperature anomalies over the ocean - data sites

Figure 2: Iconic PMIP graphics to show how well models represent the increase and northward extent of the mid-Holocene West African monsoon and the Last Glacial Maximum land-sea contrast through the different phases of PMIP. (Top) Summary of the data constraints. Temperature anomalies compiled from MARGO Project Members (2009) and Bartlein et al. (2011); biome reconstruction from Joussaume et al. (1999).

et al. 2010). The Last Millennium in PMIP is associated with the PAGES $2 \mathrm{k}$ Network and the need to improve pre-industrial reference climates (Schmidt et al. 2011). Several fresh water flux experiments have also been regularly discussed, either for the Holocene 8.2 kyr event (see Gregoire and Morrill, this issue) or complementary experiments around the LGM. Recently the deglaciation has become one of the major flagships for PMIP simulations (Ivanovic et al. 2016).

The current organization into eight working groups (pmip.Isce.ipsl.fr/working_groups) favors exchanges on the different climatic periods, transverse analyses for modeldata comparisons, and cross-period analyses. Five PMIP experiments have been included in CMIP6 (Fig. 1). More details of the PMIP journey are available online: www.tiki-toki.com/timeline/entry/1566548/ HISTORY-OF-PMIP

\section{What do PMIP iconic figures tell us about advances in modeling?}

The two PMIP iconic figures presented in Joussaume and Taylor (this issue) are reproduced here to provide an overview of how simulated changes in mid-Holocene precipitation or in LGM land-sea contrast has been represented with increasing model complexity and resolution throughout the four phases of PMIP (Fig. 2). Figure 2 illustrates the 30-year quest to simulate sufficient precipitation in the Sahel-Sahara to support the reconstructed mid-Holocene vegetation cover, which has led to improved understanding of the role of global and regional feedbacks (soil, vegetation, albedo, etc.; Brierley et al. 2020). There has been a shift between PMIP phases such that models now produce more consistent representations of increased precipitation between $6^{\circ} \mathrm{N}$ and $16^{\circ} \mathrm{N}$, but continue to struggle to reproduce the large observed changes from $16^{\circ} \mathrm{N}$ to $30^{\circ} \mathrm{N}$.

For the LGM, PMIP results have consolidated the understanding of the ratio between temperature over land and over the ocean, which is relevant for discussions about future climate (Stocker et al. 2013). Independent reconstructions over land and ocean support this ratio, and can be used to define which of the results better fits with past conditions. The current generation of climate models and new proxy reconstructions produce a large range of results, however, suggesting that the debate on the LGM land-sea ratio has not yet been resolved (Kageyama et al. 2021).

Paleoclimate modeling and systematic benchmarking within PMIP have demonstrated that feedbacks from ocean and vegetation are needed to reproduce climate changes at global or regional scales. PMIP has also demonstrated that models that produce good simulations of present-day climate do not necessarily have good skill in simulating past changes. This raises questions about how to pre-select models only looking at modern conditions when considering future climate projections, for example for impact studies. The current phase of PMIP should provide a wider range of past constraints from the combination of the different climate periods to isolate missing mechanisms or the impact of model biases on the seasonal, annual, or interannual-tocentennial scale characteristics of climate changes.

\section{In conclusion}

During the last 30 years PMIP has provided a scientific basis to define the level of model complexity needed to understand climate change processes and interactions between the different timescales fully. This is one of the reasons why PMIP results serve as reference in IPCC assessment reports (Kageyama et al. this issue, p. 68). Little by little, paleoclimate simulations are no longer being considered just to check confidence in the models, but also as a necessary step for identifying model deficiencies and contributing to the improvement of the physical and biogeochemical content of the models. Paleoclimate simulations represent an essential element in understanding climatic events with a high impact on ecosystems or societies.

\section{AFFILIATIONS}

${ }^{1}$ Laboratoire des Sciences du Climat et de I'Environnement, LSCE/IPSL, UMR CEA-CNRS-UVSQ, Université Paris-Saclay, Gif sur Yvette, France ${ }^{2} \mathrm{~S}$ chool of Archaeology, Geography and Environmental Science (SAGES), University of Reading, UK

${ }^{3}$ National Center for Atmospheric Research, Boulder, CO, USA

${ }^{4}$ Atmosphere and Ocean Research Institute, The University of Tokyo, Japan

\section{CONTACT}

Pascale Braconnot: pascale.braconnot@lsce.ipsl.fr

\section{REFERENCES}

Bartlein PJ et al. (2011) Clim Dyn 37: 775-802

Braconnot P et al. (2003) CLIVAR Exchanges 28: 19-20

Braconnot P et al. (2007) Clim Past 3: 261-277

Braconnot P et al. (2010) CLIVAR Exchanges 56: 15-19 Braconnot P et al. (2012) Nat Clim Chang 2: 417-424 Brierley CM et al. (2020) Clim Past 16: 1847-1872 Crucifix M et al. (2005) Eos 86: 264-264 Crucifix M et al. (2012) Eos 93: 539-539 Crucifix M et al. (2014) PAGES Mag 22: 103 Harrison SP et al. (2002) Eos 83: 447-447 Haywood AM et al. (2010) Geosci Model Dev 3: 227-242 Haywood AM et al. (2011) Eos 92: 180-180

Ivanovic RF et al. (2016) Geosci Model Dev 9: 2563-2587

Joussaume S, Taylor KE (1995) Status of the paleoclimate modeling intercomparison project, Proceedings

of the first international AMIP scientific conference, WCRP Report, 425-430

Joussaume S et al. (1999) Geophys Res Lett 26: 859-862 Kageyama M et al. (2018) Geosci Model Dev 11: 1033-1057

Kageyama M et al. (2021) Clim Past 17: 1065-1089 Liu J et al. (2021) PAGES Mag 29: 57

MARGO Project Members (2009) Nat Geosci 2: 127-132 Otto-Bliesner BL et al. (2009a) Eos 90: 93-93

Otto-Bliesner BL et al. (2009b) PAGES news 17: $42-43$

Otto-Bliesner BL et al. (2017) Geosci Model Dev 10: 3979-4003

Peterschmitt J-Y et al. (2018) PAGES Mag 26: 60-61 Schmidt GA et al. (2011) Geosci Model Dev 4: 33-45 Schmittner A et al. (2011) PAGES news 19: 83-84 Stocker TF at al. (Eds; 2013) Climate Change 2013: The Physical Science Basis. Cambridge University Press, $1535 \mathrm{pp}$

Zhang Q et al. (2017) PAGES Mag 25: 160 